\title{
New and practical mathematical model of membrane fouling in an aerobic submerged membrane bioreactor
}

\author{
Zuthi, Mst Fazana Rahman ${ }^{\mathrm{a}, \mathrm{b}}$, Guo, Wenshan ${ }^{\mathrm{a}}$, Ngo, Huu Hao. $^{\mathrm{a} *}$, Nghiem, Duc Long ${ }^{\mathrm{c}}$, \\ Hai, Faisal. I. ${ }^{\mathrm{c}}$, Xia, Siqing ${ }^{\mathrm{d}}, \mathrm{Li}, \mathrm{Jianxin}^{\mathrm{e}}, \mathrm{Li}, \mathrm{Jixiang}^{\mathrm{f}}$, Liu, Yi ${ }^{\mathrm{f}}$ \\ ${ }^{a}$ School of Civil and Environmental Engineering, University of Technology Sydney, Sydney, \\ NSW 2007, Australia \\ ${ }^{b}$ Department of Civil Engineering, Chittagong University of Engineering and Technology, \\ Chittagong-4349, Bangladesh. \\ ${ }^{c}$ School of Civil Mining and Environmental Engineering, University of Wollongong, \\ Wollongong, NSW 2522, Australia \\ ${ }^{d}$ School of Environmental Science and EngineeringTongji UniversityShanghaiP.R. China \\ ${ }^{e}$ State Key Laboratory of Separation Membranes and Membrane Processes, School of Materials \\ Science and Engineering, Tianjin Polytechnic University, Tianjin 300387, China \\ ${ }^{f}$ Shanghai Advanced Research Institute, Chinese Academy of Science, Zhangjiang Hi-Tech \\ Park, Pudong, Shanghai, China \\ * Corresponding author: School of Civil and Environmental Engineering, University of \\ Technology, Sydney (UTS), P.O. Box 123, 15 Broadway, Ultimo, NSW 2007, Australia. Tel.: \\ +61 29514 2745; Fax: +61 29514 2633. E-mail address: h.ngo@uts.edu.au or \\ ngohuuhao121@gmail.com
}

\begin{abstract}
This study aimed to develop a practical semi-empirical mathematical model of membrane fouling that accounts for cake formation on the membrane and its pore blocking as the major processes of membrane fouling. In the developed model, the concentration of mixed liquor suspended solid is used as a lumped parameter to describe the formation of cake layer including the biofilm. The new model considers the combined effect of aeration and backwash on the foulants' detachment from the membrane. New exponential coefficients are also included in the model to describe the exponential increase of transmembrane pressure that typically occurs after the initial stage of an MBR operation. The model was validated using experimental data obtained from a lab-scale aerobic sponge-submerged membrane bioreactor (MBR), and the simulation of the model agreed well with the experimental findings.
\end{abstract}


Keyword: Mathematical model, Membrane fouling, Pore blocking resistance, Cake layer resistance, Membrane bioreactor.

\section{Introduction}

Membrane bioreactor (MBR) has been increasingly used for wastewater treatment around the world because of its smaller physical footprint, lower sludge production, and much higher removal efficiency compared to conventional activated sludge systems.

Despite its proven advantages over conventional wastewater treatment, membrane fouling is still a major hindrance to the widespread commercial application of the MBR technology. Fouling results in reduced productivity and frequent cleaning or replacement of membrane demanding higher energy and operating cost (Kim et al., 2013; Mannina and Cosenza 2013; Zhang et al., 2014). Numerous studies have so far been conducted to identify/investigate the foulants (Gao et al., 2013; Lin et al., 2009; Tian et al., 2011; Wang et al., 2015), the processes involved with fouling (Kim et al., 2013; Qi et al., 2016; Wang et al., 2015; Zhang et al., 2016), and hence to devise strategies to control fouling (Deng et al., 2015, 2016; Drews, 2010; Mannina and Cosenza, 2013; Meng et al., 2009) for more efficient operation of the MBR systems. However, membrane fouling is a highly complex phenomenon and an accurate prediction of the fouling behaviour is still a major challenge for researchers (Cosenza et al., 2013) pursuing further research in this area.

The membrane fouling is often simultaneously caused by more than one mechanism, and can broadly be categorized as internal fouling and external fouling. Suspended particles of comparable sizes of the membrane pore (colloids) and of smaller sizes than the membrane pore (soluble particles) cause internal fouling by pore clogging and pore constriction (Busch et al., 2007). External fouling is ascribed to the cake layer formation 
associated as well with the formation of biofilm. In most of the studies, fouling due to the cake layer formation is considered as the major mechanism of fouling (Gao et al., 2013; Lin et al., 2009; Meng et al., 2009; Pendashteh et al., 2011).

The cake layer on membrane is formed by particle; larger than the membrane pores and the process is dependent on the concentration of MLSS, membrane flux and the scouring energy induced by the aeration (Giraldo and LaChevallier, 2006). An optimal concentration of MLSS in the bioreactor is considered as of critical concern for the successful operation of an MBR system since the activated sludge with MLSS concentrations exceeding $10 \mathrm{~g} / \mathrm{L}$ may lead to worse filterability (Ferreira et al., 2010). However, the MLSS concentration is a key but poorly understood operational parameter linked to filtration resistance as far as the subdivisions of the membrane foulants are concerned to identify components of cake layer, biofilm or other associated factors. Apart from identifying the effects of gross MLSS concentration on fouling, soluble microbial products (SMPs) and extra cellular polymeric substances (EPS) have appeared as critical concerns when found integrated within the cake layer formation. Moreover, the time-dependent characteristics of most fouling mechanisms can further add to the complexity of membrane fouling in MBR applications. As a consequence, mathematical model-based approach has been adopted by researchers to gain further insight of the fouling phenomena especially in regards to the complex interactions among the physio-biochemical conditions within MBR. A significant number of modelling studies have been performed on membrane fouling employing resistance-inseries model in the last decade. Most of the models are basically based on cake layer formation, concentration polarization and irreversible resistance etc. (Li and Wang, 2006; Mannina et al., 2011; Navaratna et al., 2012; Wintgens et al., 2003) and 
especially considering biofilm formation, and effect of aeration and backwash (Busch et al., 2007; Giraldo and LeChevallier (2006); Nagaoka et al. 1998). However, separate descriptions of the complex effects of different fouling processes and foulants' removal processes could hardly be integrated to correlate well with basic external measures of fouling such as the practically observed TMP differences during the operation of MBR systems. None of the above studies has taken into account the combined effects of aeration and backwashing on membrane fouling.

In this context, this paper describes the development of a simple mathematical model of membrane fouling accounting pore blocking and cake formation as the major fouling processes taking into account the combined effect of aeration and backwash. The proposed mathematical expressions for the membrane fouling processes necessarily include differential equations with time-dependent variables and constants. Also the concept of exponential increase of TMP especially after the initial stage of operation of MBR are included in the new model. The model was calibrated using experimental data obtained from a lab-scale SSMBR operated at a constant flux. The verification of model was done for additional data of the SSMBR and the experimental results of a conventional MBR as well.

\section{Materials and Methods}

\subsection{Experimental set-up}

The experiment was performed on a lab-scale SSMBR system. Specifications of the membrane module, sponge and operating conditions of the continuously aerated SSMBR system are shown in Table 1. Both the influent and effluent flow rates were controlled by a two channel pump while a separate pump was used for periodic backwashing of the membrane. A pressure gauge was used to measure the 
transmembrane pressure (TMP), and a hose air diffuser was used to provide air while an airflow meter was used to maintain a constant air flow rate at $2.2 \mathrm{~L} / \mathrm{m}^{2}$ (membrane surface).h. Before starting the experiment, the sponges used in the SSMBR were acclimatized with the synthetic wastewater to be treated for 25 days.

\section{Table 1}

The sponge used in the SSMBR was reticulated porous polyester-urethane sponge (PUS) and the optimum size of the sponge was used as determined previously according to critical flux experiments by Guo et al. (2008). The activated sludge was taken from a local wastewater treatment plant and was acclimatized with synthetic wastewater before using it in the SSMBR system. The initial MLSS concentration in the bioreactor was set approximately at $5 \mathrm{~g} / \mathrm{L}$ considering the high volumetric air flow rate used in the SSMBR system. The synthetic wastewater mainly contained glucose, ammonium sulphate, potassium dihydrogen orthophosphate and trace nutrients, and the composition of it was the same as was used in the study by Lee et al. ( 2003) . $\mathrm{NaHCO}_{3}$ or $\mathrm{H}_{2} \mathrm{SO}_{4}$ was used to adjust the synthetic wastewater $\mathrm{pH}$ to 7 .

\subsection{Mode of the MBR Operation}

The operation of full-scale MBR systems are typically done with MLSS concentrations in the range of 8 to $18 \mathrm{~g} / \mathrm{L}$ (Drews 2010). Among the two common practices in the operation of the MBR systems, one is to keep the MLSS concentration fixed more or less around a certain value which, however, needs frequent removal of excess sludge or activated sludge from the mixed liquor to avoid any instability in the operation of treatment such as to avoid the rapid rise of TMP. In the continuously operated MBR systems without sludge removal, the concentration of MLSS often increases steadily in 
most of the MBR systems depending on the feed characteristics and microbes present in the sludge (Hernandez et al., 2015). From the operational point of view, the latter practice of the MBR operation may offer advantages, for example it may promote more nitrification process due to the development of nitrifying bacterial community in the increased MLSS concentration (Kornboonraksha and Lee, 2009). Nevertheless, the excess activated sludge may need to be withdrawn in the continuously operated MBR systems to maintain its operation for longer term or to avoid any sudden instability in its operation. In a study of an MBR system for treating domestic wastewater, Hasar et al.( 2002) had to withdraw sludge in two stages to sustain stability in the operation of the system as the MLSS steadily increased to much higher value resulting in rapid rise of TMP. A continuously operated MBR was studied in this research but a small portion of sludge was withdrawn after 32 days of operation to avoid rapid rise in TMP.

\subsection{Methods of analysis}

The biological parameters were periodically measured during the period of the SSMBR's operation. The MLSS of the sludge samples were analysed daily according to standard methods (APHA, 1998). The concentrations of SMP were analysed according to modified method of Le-clech et al. (2006) and Menniti and Morgenroth ( 2010) .After centrifugation of fresh 50 mL of mixed liquor sample was @ 3500 rpm for 30 mins, the supernatant was then decanted carefully and filtered using glass fiber filter (Whatman 934-AH) with a nominal pore size of $1.2 \mu \mathrm{m}$. The filtrate was further filtered using a $0.2 \mu \mathrm{m}$ cellulose acetate filter for the analysis of SMP, and then SMP was quantified as COD of the sample. COD analysis was done by COD reagent (HANNA instruments) following their prescribed procedure. 


\subsection{Measurements of resistances}

Before commencing the experiment, the intrinsic membrane resistance was measured in distilled water at various fluxes in the range of 5 to $30 \mathrm{~L} / \mathrm{m}^{2} . \mathrm{h}$ flux at the increment of $5 \mathrm{~L} / \mathrm{m}^{2}$.h. At the end of experiment, the membrane module was taken out of the bioreactor and submerged in distilled water to measure the total resistance $\left(R_{\mathrm{T}}=R_{\mathrm{m}}+\right.$ $R_{\mathrm{p}}+R_{\mathrm{c}}$ ) of the fouled membrane. $R_{\mathrm{T}}$ is the total resistance which is the combination of membrane's intrinsic resistance $\left(R_{\mathrm{m}}\right)$, pore fouling resistance $\left(R_{\mathrm{p}}\right)$ and cake layer resistance $\left(R_{\mathrm{c}}\right)$. Darcy's law was applied to calculate total membrane resistances $\left(R_{\mathrm{T}}\right)$ following Eq. 01:

$$
J=\frac{\mathrm{TMP}}{\mu R_{\mathrm{T}}}
$$

where $J$ is the permeate flux; TMP is the transmembrane pressure, $\mu$ is the viscosity of the permeate at $20^{\circ} \mathrm{C}$.

The fouled membrane was cleaned with distilled water first by gently shaking and thereafter by using a soft spatula, made of sponge, to remove the deposited sludge cake layer from the membrane surface, and then the resistance $\left(R_{\mathrm{p}}+R_{\mathrm{m}}\right)$ was measured in distilled water. Finally, the membrane was chemically cleaned with $2 \%$ citric acid for 6 hours to remove internal pore fouling, and then cleaned with $0.4 \% \mathrm{NaOCl}$ and $4 \%$ $\mathrm{NaOH}$ for 6 hours to determine the intrinsic membrane resistance $\left(R_{\mathrm{m}}\right)$ again. For the calculation of daily total resistances from the measurements of TMP, the value of $\mu$ was corrected for temperature as follows (Delrue et al., 2011);

$$
\mu_{\mathrm{T}}=\mu_{20} e^{-.0239(\mathrm{~T}-20)}
$$

where $T$ is the temperature of mixed liquor temperature in ${ }^{\circ} \mathrm{C}$.

\subsection{Estimation of parameters of mathematical model}


The mathematical model equations were solved in Matlab 2014a based on the measured TMP, fouling resistances, MLSS and SMP concentrations in the bioreactor of the SSMBR. The algorithm used in the solution process was that of a nonlinear regression analysis using fitnlm function. The process was run with different initial values of parameters to ensure a maximum and acceptable value of $R^{2}$ (squared value of the coefficient of variance).

\subsection{Model development}

In the simplified approach of mathematical modelling, the development of fouling of the membrane is linked with biological indicator parameters such as the concentrations of SMP and MLSS in the bioreactor. In this regard, the dynamic membrane fouling is considered occurring in two major phases.

- The internal pore fouling of the membrane is assumed to occur by the adsorption of soluble particles within/onto the pores (e.g. SMP).

- The external cake layer resistance to flux is assumed to occur as the main fouling resistance integrated in which is the resistance due to biofilm.

\subsubsection{Resistance due to pore blocking}

A fraction of soluble products is adsorbed within the pores, and therefore reduces the effective pore sizes as well as the surface porosity of the membrane causing the internal pore fouling of the membrane. The soluble particles that are considered to cause pore blocking of the membrane are the SMPs (soluble EPS of the microbial products). The mathematical formulation of internal pore fouling is typically expressed by relationships of pore blocking resistance with progressive reduction of the effective pore radius $\left(r_{\mathrm{p}}\right)$ and effective porosity $(f)$ of the membrane as shown by Eq. 03 . 


$$
R_{\mathrm{p}}=e^{\left(n_{\mathrm{p}} \mathrm{t}\right)} \frac{8 h_{\mathrm{m}}}{f r_{\mathrm{p}}^{2}}
$$

where $h_{\mathrm{m}}=$ membrane's effective thickness. The expression for $R_{\mathrm{p}}$ was first proposed by Wiesner and Aptel (1996) and later modified by Bowen et al. (1997). An extension of the mathematical expression for $R_{\mathrm{p}}$ is proposed by introducing an exponential term with a factor $n_{\mathrm{p}}$ to better explain the typically observed exponential rise of TMP especially after the initial stages of operation of an MBR system. The mass balance equation for particles around the membrane causing the reduction of porosity is calculated following Busch et al. (2007).

$$
\rho_{\mathrm{p}} \frac{\mathrm{d} f}{\mathrm{~d} t}=-4 \eta_{\mathrm{f}} J(t) \mathrm{c}_{\mathrm{SMP}}(t) \frac{m_{\mathrm{d}, \mathrm{o}}}{\left(m_{\mathrm{d}, \mathrm{o}}\right)^{2}-\left(m_{\mathrm{d}, \mathrm{i}}\right)^{2}} \quad \text { Eq. } 04
$$

where $\rho_{\mathrm{p}}$ is the density of biomass, $c_{\mathrm{SMP}}$ is the concentration of soluble particles entering the pores which may be taken as $c_{\mathrm{SMP}}$ in the bioreactor, $\eta_{\mathrm{f}}$ is the average fraction of soluble particles that accumulate in the pores, $\mathrm{m}_{\mathrm{d}, \mathrm{o}}$ and $\mathrm{m}_{\mathrm{d}, \mathrm{i}}$ are the membrane outer and inner diameter respectively. Equation 04 can be rewritten as shown in Eq. 05 following the basic equation proposed by Giraldo and LeChevallier (2006).

$$
\frac{\mathrm{d} f}{\mathrm{~d} t}=-\alpha_{\mathrm{f}} c_{\mathrm{SMP}}(t) J(t)
$$

where $\alpha_{f}$ is the membrane porosity reduction coefficient to be determined from Eq. 06

$$
\alpha_{\mathrm{f}}=\frac{1}{\rho_{\mathrm{p}}} \cdot \frac{4 \eta_{\mathrm{f}} m_{\mathrm{d}, \mathrm{o}}}{\left(m_{\mathrm{d}, \mathrm{o}}\right)^{2}-\left(m_{\mathrm{d}, \mathrm{i}}\right)^{2}} \quad \text { Eq. } 06
$$

The differential equation to account for the effect of pore size reduction due to the adsorption of soluble particles within the pores is given in Eq. 07 Giraldo and LeChevallier (2006).

$$
\frac{d r_{\mathrm{p}}}{d t}=-\alpha_{\mathrm{p}} \mathrm{c}_{\mathrm{SMP}}(t) J(t) \quad \text { Eq. } 07
$$


where, $\alpha_{\mathrm{p}}=$ pore size reduction coefficient. The concentration of SMP in the bioreactor $\left(\mathrm{c}_{\mathrm{SMP}}\right)$ is a time dependent variable which depends on the design and operation of an MBR system, particularly depending on the initial concentrations of MLSS.

\subsubsection{Resistance due to cake layer formation}

External membrane fouling is caused by the deposition of cake layer over the membrane surface which gradually grows in size and thickness over time. It was found in the earlier studies that the membrane fouling generally increases with the increase in the MLSS concentrations (Kornboonraksa and Lee, 2009) that mainly contribute to the progressive formation of cake layer on the membrane surface. The formation of the cake layer on the membrane surface integrates in it the formation of biofilm. However, the cake layer resistance due to the formation of biofilm is a complex process in the mathematical modelling, especially due to the hardly understood process of the detachment of biofilm (Busch et al., 2007). As the formation of biofilm is inevitable in an MBR system and is acknowledged as one of major causes of membrane fouling (Gao et al., 2013), fouling prediction would not be complete without taking it into consideration. Consequently, the formation and detachment of the biofilm layer is not separately treated in the mathematical modelling, but is assumed to be integrated in the process of the formation and detachment of the cake layer. The concentration of MLSS in the bioreactor is taken as a gross parameter affecting the cake layer formation on the membrane while the dynamic effects of the formation of biofilm and cake layer is accounted for by taking the changes of MLSS concentrations in the model formulations.

Due to the continuous aeration and periodic backwashing in the MBR system, part of the cake layer is detached from the membrane surface back into the mixed liquor suspension. An average rate of detachment of the cake layer $(k)$ is assumed to represent 
this phenomenon which is accounted in the mass balance equation of the formation of cake layer over the membrane surface. In this simplified mathematical model, the variation of concentrations of MLSS (lumped parameter including SMP and bEPS and other microorganisms) in the bioreactor is assumed to be linked with the net rate of the attachment of cake layer (including biofilm) on the membrane surface. The cake filtration effects accounting the cake compressibility is included in the mathematical expressions of cake resistance $\left(R_{c}\right)$ as shown in Eq. 08 .

$$
R_{\mathrm{c}}=\alpha_{\mathrm{c}} h_{\mathrm{c}}(t) \rho_{\mathrm{c}} e^{\left(n_{\mathrm{c}} \mathrm{t}\right)}
$$

Eq. 08

where $\alpha_{c}=$ specific resistance of the compressible cake layer, $h_{\mathrm{c}}=$ variable depth of the cake layer expressed as a first order differential function in time. Considering the mass balance of the cake forming particles (e.g. MLSS) over the membrane surface, the $h_{\mathrm{c}}$ can be expressed in the following differential equation:

$$
\rho_{\mathrm{c}} \frac{\mathrm{d} h_{\mathrm{c}}}{\mathrm{d} t}=J \cdot(1-\mathrm{k}) c_{\mathrm{c}}(t)
$$

where $c_{\mathrm{c}}=$ concentration of potential cake forming particles in the bulk liquid (e.g. MLSS ) which typically varies over time, $\rho_{c}=$ density of the cake layer.The factor $k$ accounts for the detachment of the cake layer from the membrane surface a reasonable value for which may be determined from the model calibration. The depth of the cake layer $\left(h_{c}\right)$ is calculated from the solution of Eq. 09 and is replaced in Eq. 08 to calculate the value of $R_{\mathrm{c}}$. Finally, the total resistance is calculated from the equation of the resistance-in-series model as follows:

$$
R_{\mathrm{T}}=R_{\mathrm{m}}+R_{\mathrm{p}}+R_{\mathrm{c}}
$$

Here the intrinsic membrane resistance $\left(R_{\mathrm{m}}\right)$ is a static component in the mathematical expression which can be determined experimentally, but the total membrane resistance $\left(R_{\mathrm{T}}\right)$ becomes a dynamic variable as it includes $R_{\mathrm{p}}$ and $R_{\mathrm{c}}$. The external physical 
parameter indicative of the membrane fouling at any stage of the operation of an MBR system is the TMP (or $\Delta P$ ). The state of fouling of the membrane at any instance of time ( $t$ ) can be obtained from the current $\operatorname{TMP}(t)$ the mathematical expression for which are related to the respective measured data of flux $(J)$ and total internal resistance $\left(R_{\mathrm{t}}\right)$ to flux according to Darcy's law as shown in Eq. 01.

\section{Results and Discussion}

\subsection{Variation of MLSS and SMP with operation time}

In this study, the SSMBR system was operated upto 49 days starting with the initial MLSS concentration of $5 \mathrm{~g} / \mathrm{L}$. The MLSS concentration steadily increased to 18.8 $\mathrm{g} / \mathrm{L}$ upto 32 days of operation of the system when the rapid rise of TMP was first observed. Consequently, some sludge was withdrawn (to reduce the MLSS concentration around $10 \mathrm{~g} / \mathrm{L}$ ) after 32 days to avoid the rapid rise in TMP. The MLSS again steadily increased from $10 \mathrm{~g} / \mathrm{L}$ to $17 \mathrm{~g} / \mathrm{L}$ up to 49 days when the operation of the system was terminated since the TMP increased to about $50 \mathrm{kPa}$.

The effects of the withdrawal of sludge at 32 days were also evident in the concentrations SMP in the bioreactor of the SSMBR. The concentration of SMP in the bioreactor of MBR depends on the microbial activity, membrane rejection efficiency and many other factors. During the first 32 days of operation of the SSMBR, the SMP concentration was found in the range of 15 to $39 \mathrm{mg}$ COD/L but relatively lower SMP concentrations ( 15 to $22 \mathrm{mg} \mathrm{COD/L}$ ) were found in the latter stage of the operation period. Menniti and Morgenroth (2010) studied an MBR system under different operating conditions created by high shear and low shear aerations and with different 
membrane size. In the high shear MBR, the SMP concentration in the bioreactor was found to be around 50 to $100 \mathrm{mg} \mathrm{COD} / \mathrm{L}$, while the SMP concentration in the low shear MBR varied within the range between 50 and $350 \mathrm{mg} \mathrm{COD} / \mathrm{L}$.

\subsection{Model analysis and application}

\subsubsection{Inputs for model calibration}

In the calibration of the model, the MLSS and SMP concentrations in the bioreactor are input, and these are the best representative mathematical functions of time obtained from experimental data for the solution of Eq. 07 and Eq. 09. The data chosen to derive the functions are the representative data measured during the first 30days of the operation of the SSMBR system. The variation of the concentrations of MLSS (in g/L) up to 32 days of operation of the system can be best represented by a linear function with a reasonably good correlation coefficient $\left(R^{2}=0.95\right)$, as shown in Eq. 11 and in Figure 1.

$$
\text { MLSS }=0.41 t+5.6
$$

Eq. 11

Where $t$ represents the days of operation of the SSMBR. In any continuously operated MBR systems with no sludge withdrawal, the MLSS concentrations mostly increase at a steady rate (Harnendez et al., 2009; Kornboonraksha and Lee, 2012). Therefore, this type of best approximated function may be developed for the typical MBR system's operation.

\section{Figure 1}

The variations of the concentrations of SMP in the bioreactor for the first 32 days of operation of the MBR can be better represented by power function $\left(R^{2}: 0.79\right)$, as shown in Eq. 12 and in Figure 1. 


$$
c_{\mathrm{SMP}}=16.3 *(t)^{0.24}
$$

The numerical model simulation would be more simple if the rate of change of MLSS or SMP concentration is given as best approximated functions. The best approximated functions, as that are found in this study, may not be found in other MBR systems although with continuous operations of the system. In fact, the dynamic change of SMP concentration within bioreactor depends on the SMP growth rate, rate of degradation, the membrane rejection efficiency and many other factors. Menniti and Morgenroth (2010) found fluctuating (no trend) concentration of SMP in a high shear MBR while the SMP concentration steadily increased in a low shear MBR. However, the proposed model's simulation can also be done by the inputs of discrete value of these parameters.

With specific operational and design parameters as indicated in Table 1, the value of the membrane porosity reduction coefficient $\left(\alpha_{\mathrm{f}}\right)$ was determined to be $3.25 \mathrm{~m}^{2} / \mathrm{Kg}$ according to Eq. 06 while the value for the membrane pore size reduction coefficient $\left(\alpha_{\mathrm{p}}\right)$ is reasonably assumed to be $0.000943 \mathrm{~m}^{3} / \mathrm{Kg}\left(=1 / \rho_{\mathrm{p}}\right)$. An average value for the specific cake resistance $\alpha_{c}=1 * 10^{14} \mathrm{~m} / \mathrm{Kg}$ was adopted which fell between the upper and lower bound value as reported in the literature (Li and Wang, 2006). With other design and operational parameters (e.g. measured values of $J, \mu, R_{\mathrm{m}}$ ) of the SSMBR and the expressions for $R_{\mathrm{p}}$ and $R_{\mathrm{c}}$ are derived from Eq. 03 and Eq. 08 respectively, TMP was calculated according to Darcy's law (as shown in Eq. 01).

\subsubsection{Model calibration and reliability analysis}

The unknowns involved in the solution of the mathematical expressions have some characteristic features by definition. The coefficients $n_{\mathrm{p}}$ and $n_{\mathrm{c}}$ should preferably have 
positive values, the value of effective initial porosity of the membrane should be in the range between 5\% and 34\% (Yoon et al., 2006), and the coefficient for the rate of cake layer detachment $(k)$ should have a value between 0 and 1 . With the input values of variable TMP (experimental) for the first 32 days of operation of the MBR, the resulting equation for TMP (according to Eq. 01) could be solved by non-linear regression analysis to find unknowns and hence to simulate a reasonable TMP (Figure 2).

\section{Figure 2}

However, the unknown parameters and constants determined from the combined mathematical modelling of total resistances $R_{\mathrm{T}}\left(=R_{\mathrm{m}}+R_{\mathrm{p}}+R_{\mathrm{c}}\right)$ against experimental TMP are meaningless according to their definition in the model equations (e.g. $k>>1$ ). Although the total resistance $\left(R_{\mathrm{T}}\right)$ could be predicted fairly accurately, the boundary values of $R_{\mathrm{p}}$ and $R_{\mathrm{c}}$ as determined from these coefficients do not satisfy the values that were experimentally measured at the end of operation of the SSMBR. Therefore, the calibration of the mathematical model of membrane fouling was done separately for the two dynamic components of fouling resistances, $R_{\mathrm{p}}$ and $R_{\mathrm{c}}$. The initial and final boundary values of $R_{\mathrm{p}}$ that are used for the model calibration are zero and $3.5^{*} 10^{12} / \mathrm{m}$, respectively. Figure 3 shows simulated results of $R_{\mathrm{p}}$ with different assumed values of effective initial porosity as $7 \%, 10 \%, 15 \%$ and $25 \%$ of the membrane.

\section{Figure 3}

The values of the coefficients and constants as determined from the model simulations for $R_{\mathrm{p}}$ are then used for further simulations for TMP against $R_{\mathrm{T}}$ to determine other coefficients and constants. Table 2 shows the calculated values of all the model parameters obtained from the mathematical model simulations using the data for the first 32 days of operation of the SSMBR system. However, the respective values of cake 
layer resistance $\left(R_{\mathrm{c}}\right)$ and the pore fouling resistance $\left(R_{\mathrm{p}}\right)$ at the end of day 49 of the SSMBR's operation are also included in Table 2. Table 2 shows that the calculated values of coefficients are meaningful and reasonable when the initial porosities of membrane are below $15 \%$. The calculated rate of cake layer detachment (the value of the coefficient, $k$ ), for example, should be a positive number with a value less than 1 which could only be found when the initial porosities of the membrane was assumed to be between $7 \%$ and $15 \%$. At the same time, the assumed porosity between $7 \%$ and $15 \%$ is also a reasonable assumption for the microfiltration membrane. The cake layer resistance $R_{\mathrm{c}}$, as determined by the model simulation with assumed effective initial porosity of $15 \%$, is found to $1.205 * 10^{13} / \mathrm{m}$. The measured cake layer resistance $\left(1.07 * 10^{13} / \mathrm{m}\right)$ at day 49 , however, was less than that determined from the model simulations. This is reasonable asa fraction of the sludge was withdrawn at day 32 of the SSMBR's operation. An even better agreement with the experimentally measured pore fouling resistance $\left(R_{\mathrm{p}}\right)$ at day 49 could be found by the model simulation results as shown in Table 2. Therefore, an effective initial porosity of $15 \%$ seems to be reasonable for the membrane of the SSMBR considering the better agreement for both the boundary values of $R_{\mathrm{p}}$ and $R_{\mathrm{c}}$.

\section{Table 2}

\section{Table 3}

\subsubsection{Comparison between experimental and simulated results}

The model of membrane fouling described in this paper has introduced two new parameters $n_{\mathrm{p}}$ and $n_{\mathrm{c}}$, respectively to account for the exponential rise of dynamic resistances $R_{\mathrm{p}}$ and $R_{\mathrm{c}}$ that are typically comparable with the exponential rise of TMP 
especially after the initial stage of operation of any MBR. The model could not be calibrated against the boundary values of $R_{\mathrm{p}}$ and $R_{\mathrm{c}}$ without using these exponential parameters. Figure 4, for example, shows the model simulation results for $R_{\mathrm{p}}$ with and without using the parameter $n_{\mathrm{p}}$ in the expression for $R_{\mathrm{p}}$. It is evident from the simulation results that the rise of pore fouling resistance without exponential parameter in the model is very insignificant which does not fit the typical observations of the increase of $R_{\mathrm{p}}$ in any MBR system which is also comparable to the pattern of TMP rise.

\section{Figure 4}

Meaningful values of the model parameters and coefficients can only be calculated by the calibration of the model separately for the two dynamic components of fouling resistances, $R_{\mathrm{p}}$ and $R_{\mathrm{c}}$. The boundary values of $R_{\mathrm{p}}$ and $R_{\mathrm{c}}$ as determined by the calibrated model agree reasonably well with their experimentally determined values although only few selected experimental measures of TMP have been used for the calibration of the model. Figure 5 shows that the experimental $R_{\mathrm{p}}+R_{\mathrm{c}}$ also compares well against the daily variations of simulated $R_{\mathrm{p}}+R_{\mathrm{c}}$ particularly for the period when exponential increase of fouling resistances/ TMP occurred. Figure 5 aslo shows experimental results of total fouling resistance $\left(R_{\mathrm{T}}\right)$ against the daily variations of simulated $R_{\mathrm{T}}$ in terms of TMP. Therefore, the mathematical model can be effectively used to predict separate components of the dynamic fouling resistances along with the prediction of total fouling resistances.

\section{Figure 5}

The model simulation was also carried out to compare the rise of TMP in a conventional MBR system (CMBR, without sponges in the bioreactor) of the same type that was run with a reduced constant flux $\left(10 \mathrm{~L} / \mathrm{m}^{2} / \mathrm{hr}\right)$ but with nearly the same initial 
MLSS concentrations of the sludge $(5.7 \mathrm{~g} / \mathrm{L})$ as that of the SSMBR. The wastewater characteristics and the volume of the reactors are same in both the MBR systems. The mean pore size of the membrane of the CMBR is $0.2 \mu \mathrm{m}$. The model simulation has been done by using the calibrated model parameters and coefficients of the SSMBR, but changing the parameters relevant to the operational parameters of the CMBR (e.g.J). Figure 6 shows the model simulation results of TMP of the CMBR as compared to the experimentally measured results.

\section{Figure 6}

As it was experimentally observed for the CMBR, the exponential rise of TMP cannot be simulated well (Figure 6) without changing the exponential parameter $\left(n_{\mathrm{c}}\right)$ for the cake layer resistance $\left(R_{\mathrm{c}}\right)$. The fundamental difference between the operation of CMBR and SSMBR system is that the sponges in the bioreactor of a SSMBR act against the cake layer growth and hence reduce the exponential rise of TMP due to the formation of the cake layer. The fact is also evident in the model simulation results of the CMBR where the cake layer resistance $\left(R_{\mathrm{c}}\right)$ cannot be simulated accurately with the same value of the coefficient $n_{\mathrm{c}}$ as used for the $\operatorname{SSMBR}\left(n_{\mathrm{c}}=0.065\right)$. However, the cake layer resistance $\left(R_{\mathrm{c}}\right)$ and hence the TMP in the CMBR can be simulated reasonably well by simply changing the value of $n_{\mathrm{c}}$ to 0.140 which accounts for more rapid rise of TMP in the CMBR. Figure 6 shows the model simulation results of TMP of the CMBR with the modified value of $n_{\mathrm{c}}=0.140$ instead of 0.065 . It is evident from the model development and its subsequent simulation and validation that exponential rise in TMP should be considered devising fouling control strategies.

\section{Conclusion}


A new and practical semi-empirical mathematical model of membrane fouling has been developed in the study that accounts pore blocking and cake formation on membrane as the major processes of membrane fouling in an aerobic submerged MBR. SMPs are considered as the key components of pore fouling while MLSS are assumed as contributors of foulants of cake layer including the biofilm. The model simulation could predict reasonably well the development fouling in a lab-scale submerged MBR system. However further verification of the model is required by operating the MBR systems with different MLSS concentrations and at different operating conditions.

\section{Acknowledgments}

This study was supported by Sustainable Water Group, MBR project, Wastewater Treatment and Reuse Technologies, Centre for Technology in Water and Wastewater (CTWW), School of Civil and Environmental Engineering, University of Technology, Sydney (UTS). The authors are also grateful for the research collaboration of the joint MBR Centre founded by UTS, Tongji University and Tianjin Polytechnic University.

\section{References:}

1. APHA., AWWA., WEF., 1998. Standard Methods for the examination of Water and Wastewater. $20^{\text {th }}$ edition, American Public Health Association.

2. Bowen, W. R., Mohammad, A. W., Hilai, N., 1997. Characterisation of nanofiltration membranes for predictive purposes - use of salts, uncharged solutes and atomic force microscopy. Journal of Membrane Science 126, 91105.

3. Busch, J., Cruse, A., Marquardt, W., 2007. Modeling submerged hollow-fiber membrane filtration for wastewater treatment. Journal of Membrane Science 288, 94-111. 
4. Cosenza, A., di Bella, G., Mannina, G., Torregrossa, M., 2013. The role of EPS in fouling and foaming phenomena for a membrane bioreactor. Bioresource Technology 147, 184-192.

5. Delrue, F., Stricker, A.E, Mietton-Peuchot, M., Racault, Y., 2011. Relationships between mixed liquor properties, operating conditions and fouling on two fullscale MBR plants. Desalination 272, 9-19.

6. Deng, L., Guo, W., Ngo, H. H., Zuthi, M. F. R., Zhang, J., Liang, S., Li, J., Wang, J., Zhang, X., 2015. Membrane fouling reduction and improvement of sludge characteristics by bioflocculant addition in submerged membrane bioreactor. $156,450-458$.

7. Deng, L., Guo, W., Ngo, H. H., Du, B., Wei, Q., Tran, N. H., Nguyen, N. C., Chen, S., Li, J. 2016. Effects of hydraulic retention time and bioflocculant addition on membrane fouling in a sponge-submerged membrane bioreactor. Bioresource Technology, 210, 11-17

8. Drews, A., 2010. Membrane fouling in membrane bioreactors - characterization, contradiction, causes and cures. Journal of Membrane Science 363, 1-28.

9. Ferreira, M. L-., Geilvoet,S., Moreau,A., Atasoy,E., Krzeminski,P, van Nieuwenhuijzen, A., J. van der Graaf, J., 2010. MLSS concentration: Still a poorly understood parameter in MBR filterability. Desalination 250, 618-622.

10. Gao,W.J., Han, M.N., Qu, X., Xu, C., Liao, B.Q., 2013. Characteristics of wastewater and mixed liquor and their role in membrane fouling. Bioresource Technology 128, 207-214. 
11. Giraldo, E., LeChevallier, M., 2006. Dynamic mathematical modeling of membrane fouling in submerged membrane bioreactors. Water Environment Foundation WEFTEC®.06, 4895-4913.

12. Guo,W. S., Ngo, H. H., Vigneswaran, S., Xing, W., Goteti, P., 2008. A novel sponge-submerged membrane bioreactor (SSMBR) for wastewater treatment and reuse. Separation Science and Technology 43, 273-285.

13. Hasar, H, Kmacl, C., Unlii, A., 2002. Viability of microbial mass in a submerged membrane bioreactor. Desalination 150, 263-268.

14. Hernández, L. R-., García, A.,L., E-., Tejero, I., 2014. Comparison between a fixed bed hybrid membrane bioreactor and a conventional membrane bioreactor for municipal wastewater treatment: A pilot-scale study. Bioresource Technology 152, 212-219.

15. Kim, M., Sankararao, B, Lee, S., Yoo, C, 2013. Prediction and identification of membrane fouling mechanism in a membrane bioreactor using a combined mechanistic model. Industrial and Engineering Chemistry Research, American Chemical Society 52, 17198-17205.

16. Kornboonraksa,T., Lee, S. H., 2009. Factors affecting the performance of membrane bioreactor for piggery wastewater treatment. Bioresource Technology 100, 2926-2932.

17. Le-Clech, P., Chen, V., Fane,T.A.G., 2006. Fouling in membrane bioreactors used in wastewater treatment. Journal of Membrane Science 284 (1-2), 17-53.

18. Lee, W., Kang S., Shin, H., 2003. Sludge characteristics and their contribution to microfiltration in submerged membrane bioreactors. Journal of Membrane Science 216, 217-227. 
19. Li, X.Y., Wang, X.M., 2006. Modelling of membrane fouling in a submerged membrane bioreactor. Journal of Membrane Science 278, 151-161.

20. Lin, H. J., Xie, K., Mahendran, B., Bagley D. M., Leung, K. T., Liss, S. N., Liao, B. Q., 2009. Sludge properties and their effects on membrane fouling in submerged anaerobic bioreactors (SAnMBRs). Water Research 43, 3827- 3837.

21. Mannina, G., Cosenza, A., 2013. The fouling phenomenon in membrane bioreactors: Assessment of different strategies for energy saving. Journal of Membrane Science 4443, 32-344.

22. Mannina, G., di Bella, G., Viviani, G., 2011. An integrated model for biological and physical process simulation in membrane bioreactors, Journal of Membrane Science 376, 56-69.

23. Meng, F., Chae, S., Drews, A. Kraume, M., Shin, H., Yang, F., 2009. Recent advances in membrane bioreactors (MBRs): Membrane fouling and membrane material. Water Research 43, 1489-1512.

24. Menniti, A., Morgenroth, E., 2010.Mechanisms of SMP production in membrane bioreactors: Choosing an appropriate mathematical model structure. Water Research 44, 5240-5251.

25. Nagaoka, H., Yamanishi,S., Miya, A., 1998. Modeling of biofouling by extracellular polymers in a membrane seperation activated sludge system. Water Science and Technology 38 (4/5), 497-504.

26. Navaratna, D., Shu, L., Baskaran, K., Jegatheesan, V., 2012. Model development and parameter estimation for a hybrid submerged membrane bioreactor treating Ametryn. Bioresource Technology 113 , 191-200. 
27. Pendashteh, R., Fakhru'l-Razi, A., Madaeni, S. S., Abdullah, L. C., Abidin, Z. Z., Biak, D. R. A., 2011. Membrane foulants characterization in a membrane bioreactor (MBR) treating hypersaline oily wastewater. Chemical Engineering Journal 68, 140-150.

28. Qi, C., Wang, J., Lin, Y., 2016. New insight into influence of mechanical stirring on membrane fouling of membrane bioreactor: Mixed liquor properties and hydrodynamic conditions. Bioresource Technology 211, 654-663

29. Tian, Y., Chen, L., Zhang, S., Zhang, S., 2011. A systematic study of soluble microbial products and their fouling impacts in membrane bioreactors. Chemical Engineering Journal 168, 1093-1102.

30. Wang, C., Chen,W., Hu, Q., Ji, M., Gao, X., 2015. Dynamic fouling behavior and cake layer structure changes in nonwoven membrane bioreactor for bath wastewater treatment, Chemical Engineering Journal 264, 462-469.

31. Wiesner, M.R., Aptel, P., 1996.Mass Transport and Permeate Flux and Fouling in Pressure-Driven Processes. Water Treatment. Membrane Process, AWWAMcGrawHill.

32. Wintgens, T., Rosen, J., Melin, T., Brepols, C., Drensla, K., Engelhardt, N., 2003. Modelling of a membrane bioreactor system for municipal wastewater treatment. Journal of Membrane Science 216 (1-2), 55-65.

33. Yoon, K., Kim, K., Wang, X., Fang, D., Hsiao, B. S., Chu, B., 2006. High flux ultrafiltration membranes based on electrospum nanofibrous PAN scaffolds and chitosan coating. Polymer 47, 2434-2441.

34. Zhang, M., Peng, W., Chen, J., He, Y., Ding, L., Wang, A., Lin, H., Hong, H., Zhang, Y., Yu, H., 2013. A new insight into membrane fouling mechanism in 
submerged membrane bioreactor: Osmotic pressure during cake layer filtration. Water Research 47, 2777-2786.

35. Zhang, Y., Zhang, M.,Wang, F., Hong, H.,Wang, A., Wang, J.,Weng, X., Lin, H., 2014. Membrane fouling in a submerged membrane bioreactor: Effect of $\mathrm{pH}$ and its implications. Bioresource Technology 152, 7-14. 


\section{Figure Captions}

Figure 1: Variation of MLSS and SMP in bioreactor during first 32 days of the SSMBR operation

Figure 2: Comparison of the experimentally measured TMP and the TMP calculated from mathematical model (for the first 32 days of operation of the SSMBR)

Figure 3: Simulated $R_{\mathrm{p}}$ for various initial porosities of membrane

Figure 4: Simulated $R_{\mathrm{p}}$ with and without using the parameter $n_{\mathrm{p}}$ (for porosity of $15 \%$ )

Figure 5: Comparison of model simulation results with experimental results of SSMBR $\left(R_{\mathrm{p}}+R_{\mathrm{c}}\right.$ and TMP)

Figure 6: Comparison of simulated TMP with experimental TMP of the CMBR (with and without modified value of exponent coefficient $n_{\mathrm{c}}$ of the model) 


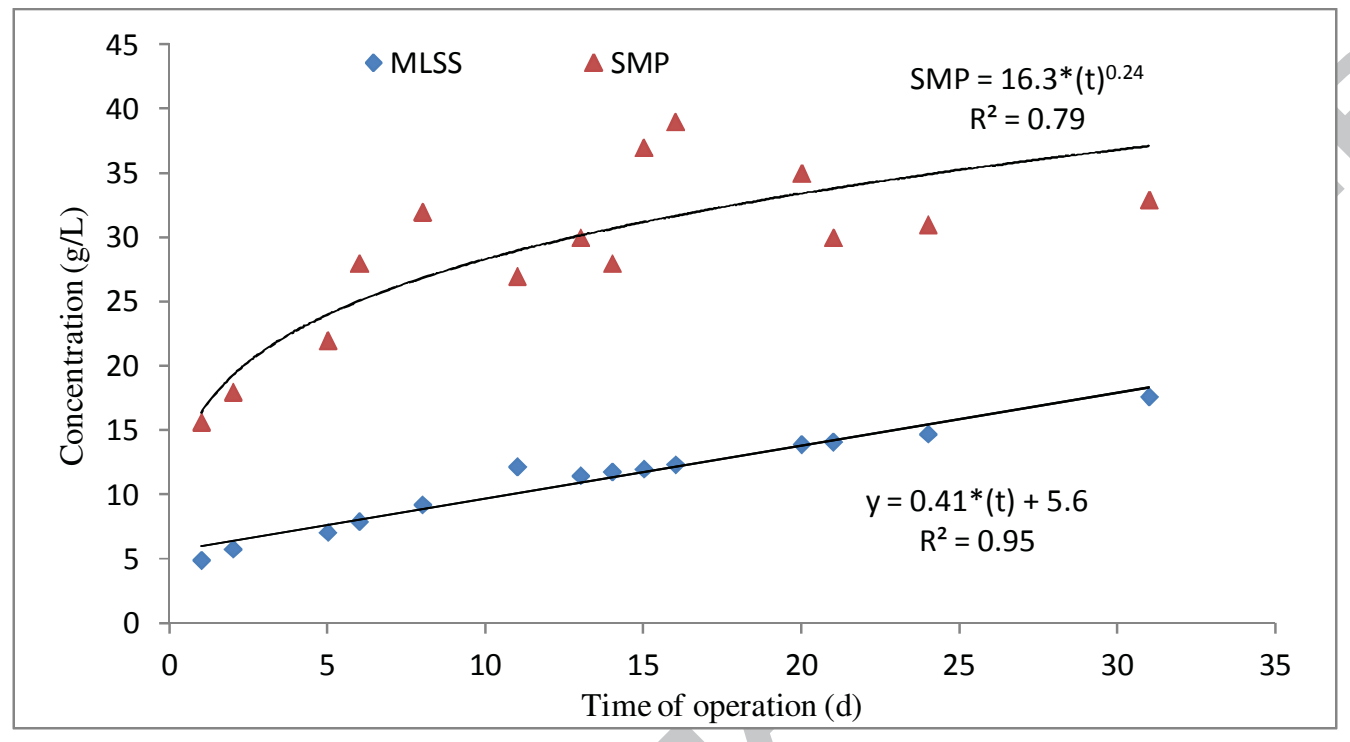

Figure 1 


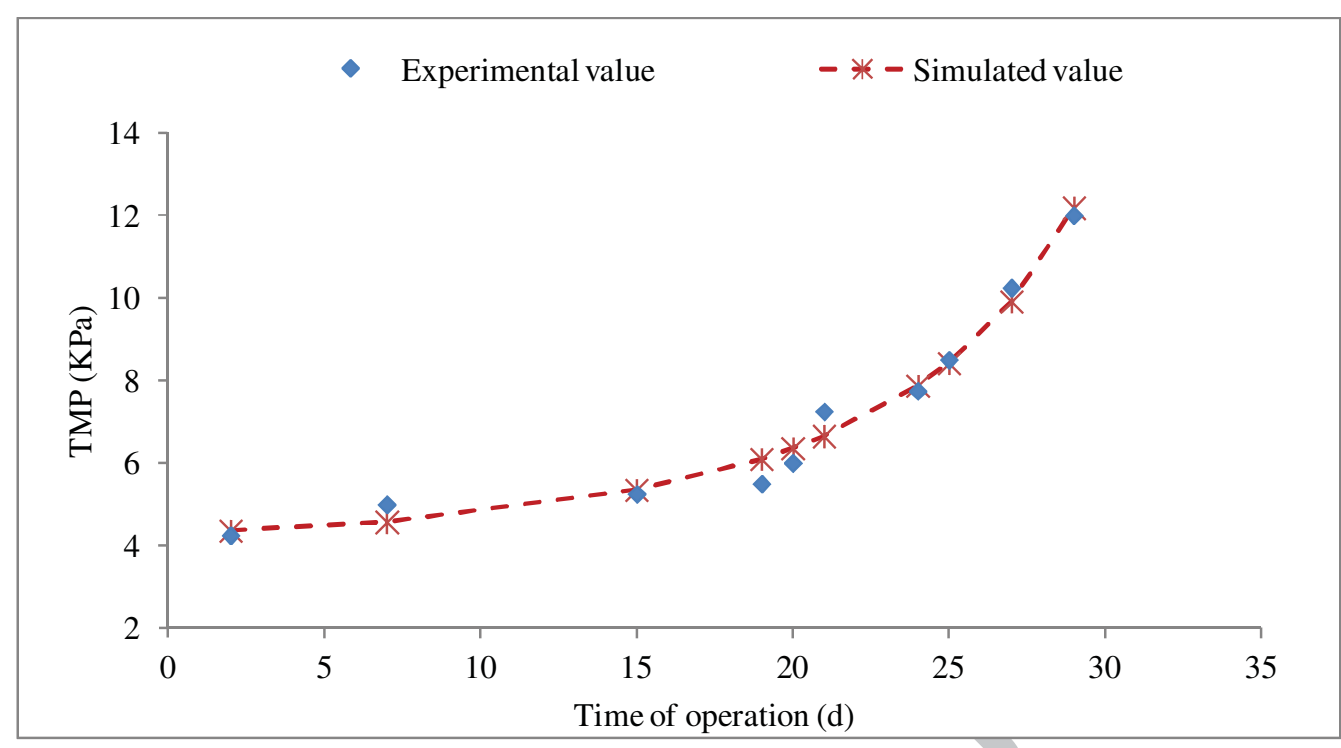

Figure 2 


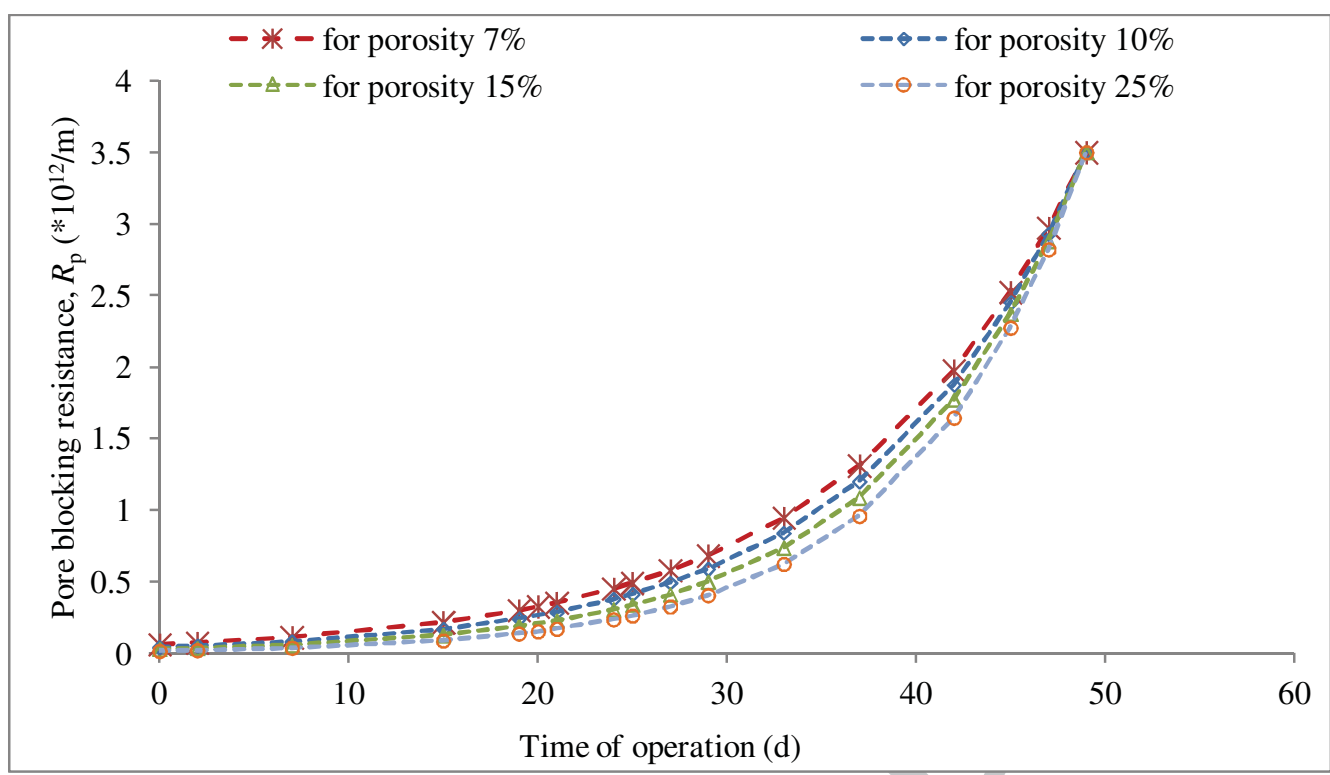

Figure 3 


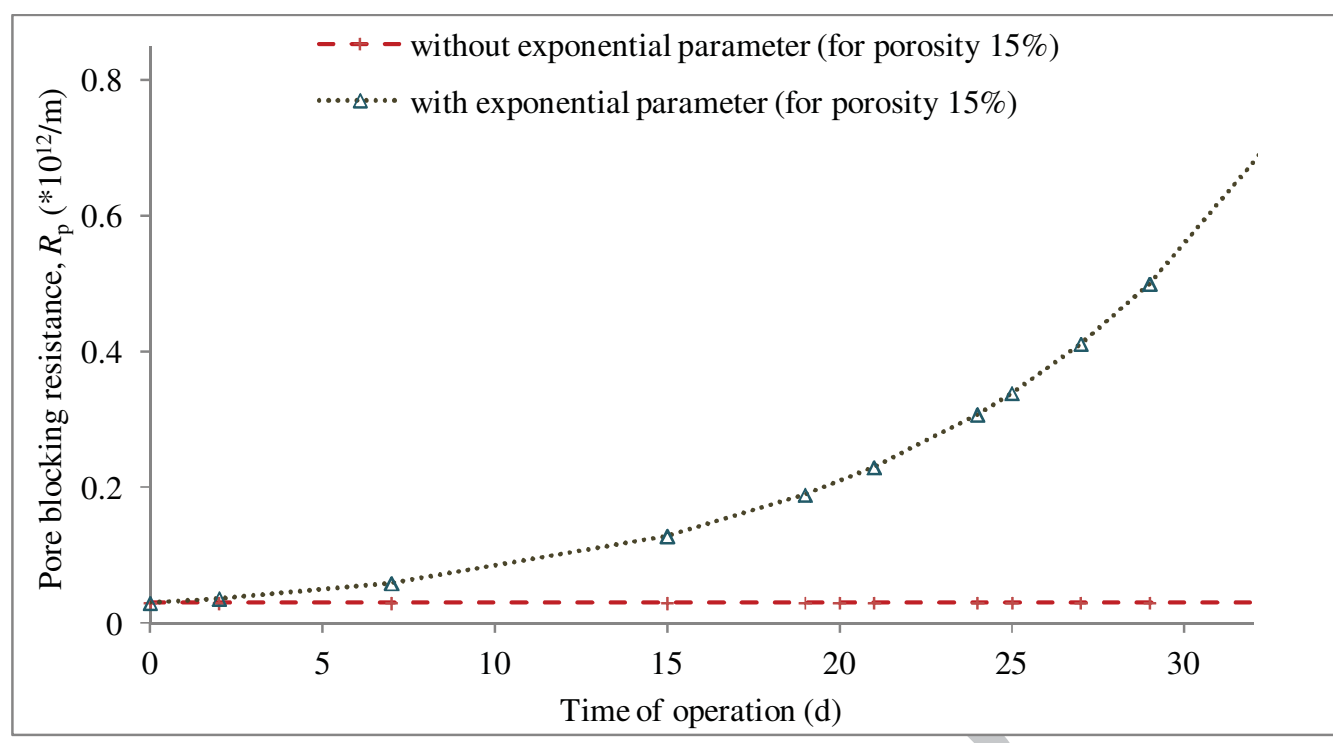

Figure 4 


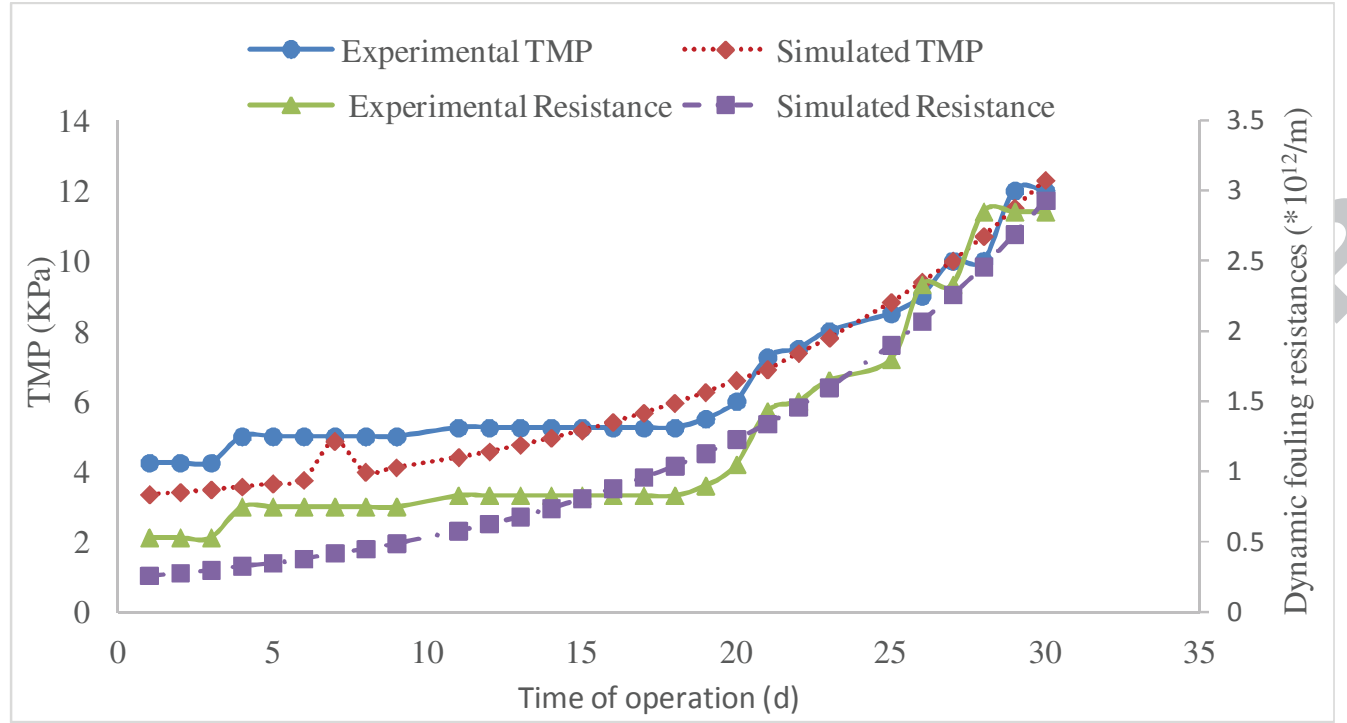

Figure 5 


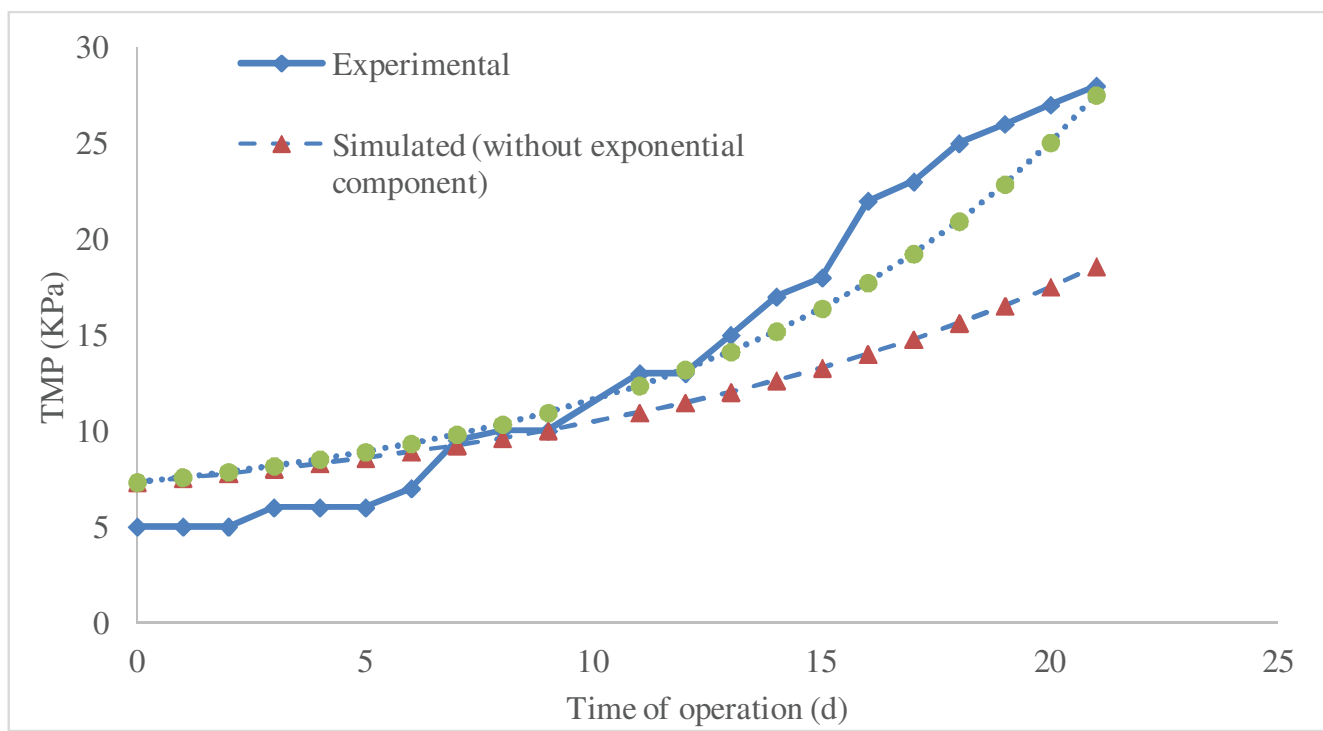

Figure 6 


\section{$\underline{\text { Table Titles }}$}

Table1: Design parameters, operating conditions and system performance of the SSMBR

Table 2: Parameters and model simulation results with various porosities of membrane Table 3: Calibrated model parameters and coefficients used in simulations 
Table 1

\begin{tabular}{|c|c|}
\hline \multicolumn{2}{|l|}{ Membrane details: } \\
\hline Membrane material & Polyethylene with hydrophilic coating \\
\hline Manufacturer & Mitsubishi-Rayon, Tokyo, Japan \\
\hline Pore size & $0.1 \mu \mathrm{m}$ \\
\hline Outer diameter, $m_{\mathrm{d}, \mathrm{o}}$ & $0.41 \mathrm{~mm}$ \\
\hline Inner diameter, $m_{\mathrm{d}, \mathrm{i}}$ & $0.27 \mathrm{~mm}$ \\
\hline Effective thickness, $h_{\mathrm{m}}=m_{\mathrm{d}, \mathrm{o}}-m_{\mathrm{d}, \mathrm{i}}$ & $0.14 \mathrm{~mm}$ \\
\hline Surface area & $0.195 \mathrm{~m}^{2}$ \\
\hline \multicolumn{2}{|l|}{ Sponge details: } \\
\hline Manufacturer's Name & Joyce Foam Products, Australia \\
\hline Material & Reticulated porous polyester-urethane (PUS) \\
\hline Density & $28-30 \mathrm{~kg} / \mathrm{m}^{3}$ with 90 cells per $25 \mathrm{~mm}$ \\
\hline Size & $1 \mathrm{~cm} \times 1 \mathrm{~cm} \times 1 \mathrm{~cm}$ \\
\hline Volume fraction of bioreactor & $10 \%$ \\
\hline \multicolumn{2}{|l|}{ Operating conditions: } \\
\hline Flux, $J\left(\mathrm{~L} / \mathrm{m}^{2} . \mathrm{h}\right)$ & 12 \\
\hline Reactor volume (L) & 10 \\
\hline MLSS (g/L) & $5-18$ \\
\hline Temperature $\left({ }^{0} \mathrm{C}\right)$ & $21-24.5$ \\
\hline Aeration rate $\left(\mathrm{L} / \mathrm{m}^{2} . \mathrm{h}\right)$ & 2.2 \\
\hline HRT (h) & 4.3 \\
\hline $\mathrm{DO}(\mathrm{mg} / \mathrm{L})$ & $7.5-8.5$ \\
\hline Operation period $(\mathrm{d})$ & 50 \\
\hline Physical cleaning frequency(Backwash) & 1 min after every 1 hour of filtration \\
\hline Backwash rate $\left(\mathrm{L} / \mathrm{m}^{2} \cdot \mathrm{h}\right)$ & 30 \\
\hline \multicolumn{2}{|l|}{ Influent characteristics: } \\
\hline $\mathrm{COD}(\mathrm{mg} / \mathrm{L})$ & $350-380$ \\
\hline $\mathrm{PO}_{4}-\mathrm{P}(\mathrm{mg} / \mathrm{L})$ & $3.1-4.0$ \\
\hline $\mathrm{NH}_{4}-\mathrm{N}(\mathrm{mg} / \mathrm{L})$ & $9-15$ \\
\hline Organic Loading Rate (g COD/L/d) & $1.96-2.1$ \\
\hline \multicolumn{2}{|l|}{ Removal efficiency $(\%)$ : } \\
\hline COD & $95-98$ \\
\hline $\mathrm{PO}_{4}-\mathrm{P}$ & $85-100$ \\
\hline $\mathrm{NH}_{4}-\mathrm{N}$ & $70-90$ \\
\hline
\end{tabular}


Table 2

\begin{tabular}{lcccc}
\hline & \multicolumn{4}{c}{ Initial porosities $(\%)$} \\
Parameters & 7 & 10 & 15 & 18 \\
\hline$K$ & 0.07 & 0.067 & 0.025 & -0.007 \\
$n_{p}$ & 0.081 & 0.089 & 0.097 & 0.107 \\
$n_{c}$ & 0.231 & 0.118 & 0.065 & 0.065 \\
$R_{\mathrm{c}}(/ \mathrm{m})$ & $1.230^{*} 10^{13}$ & $1.204 * 10^{13}$ & $1.205^{*} 10^{13}$ & $9.830^{*} 10^{14}$ \\
$R_{\mathrm{p}}(/ \mathrm{m})$ & $3.5^{*} 10^{12}$ & $3.5^{*} 10^{12}$ & $3.5^{*} 10^{12}$ & $3.5^{*} 10^{12}$ \\
\hline
\end{tabular}


Table 3

\begin{tabular}{lll}
\hline Parameter & Description & Value \\
\hline$K$ & $\begin{array}{l}\text { rate of detachment of cake layer due to the combined effects } \\
\text { of backwash and aeration }(\%)\end{array}$ & 0.025 \\
$\alpha_{\mathrm{c}}$ & specific cake resistance $(\mathrm{m} / \mathrm{Kg})$ & $1 \times 10^{14}$ \\
$\alpha_{\mathrm{f}}$ & membrane porosity reduction coefficient $\left(\mathrm{m}^{2} / \mathrm{Kg}\right)$ & 3.25 \\
$\alpha_{\mathrm{p}}$ & pore size reduction coefficient $\left(\mathrm{m}^{3} / \mathrm{Kg}\right)$ & 0.000943 \\
$n_{\mathrm{c}}$ & exponential parameter (used in cake layer resistance) & 0.065 \\
$n_{\mathrm{p}}$ & exponential parameter (used in pore resistance) & 0.097 \\
$R_{\mathrm{m}}$ & membrane's intrinsic resistance $(/ \mathrm{m})$ & $7.43 \times 10^{11}$ \\
\hline
\end{tabular}




\section{Highlights}

- Fouling in MBR occurs due to dynamic development of several fouling resistances

- Pore blocking and cake layer formation on membrane are the major processes of fouling

- $\quad$ SMP is assumed to be the major contributor of membrane pore fouling

- MLSS is assumed to contribute to the development of cake layer and biofilm formation

- New simplified model of membrane fouling can simulate well the exponential TMP rise 